\title{
Skills improvement of instructor to provide technical consultation with industries
}

\begin{abstract}
Technical training instructors play an important role in shaping students with value of employability and high workability. Human capital development of vocational instructors produce quality students who fulfil industrial requirements and in line with the national agenda towards highly skilled workers. Based on the Malaysiâ̂ Development Plan of Occupational Skill, the issues and challenges that have been identified in producing skilled workers development is a matter of less competent trainers in interpersonal and technical skills. The objective of this study was to identify and analyze the development of technical instructor for giving consultancy services to the industry. Development of technical training instructors have been formulated through Community Employment Support Services to build collaboration between the community, technical institutes and industry using three main concept or tools: Employment Support, 5S Kaizen and Curriculum Development Based on Ability Structure. The role of employers in providing training and education to employees is vital in establishing career development of employees. Employers who contributed to their employees' training funds through Human Resources Development Council would provide opportunities to increase the skills of workers. The biggest impact on high skills is customer satisfaction and increase in organizational productivity.
\end{abstract}

Keyword: Higher education; Human resources development; Training institutes; Vocational 